\title{
A MULTIPLICAÇÃO INCESSANTE DO VALOR: A DIFERENÇA ENTRE ENTESOURADOR E CAPITALISTA EM MARX
}

\begin{abstract}
ADRIANA SANTOS TABOSA ${ }^{1}$
RESUMO: A proposta deste artigo é analisar a distinção estabelecida por Marx entre "entesourador" e "capitalista". Levanta-se como hipótese que o fundamento dessa diferença reside na finalidade da multiplicação incessante do valor para ambos. Tanto o entesourador quanto o capitalista agem por um impulso pelo enriquecimento. Contudo, o entesourador acumula dinheiro como dinheiro, ao passo que o capitalista acumula dinheiro como capital. Enquanto o entesourador retém o dinheiro da circulação, o capitalista empenha-se em fazer o dinheiro circular, indefinidamente. Não obstante, parte-se do princípio que essa multiplicação incessante do valor praticada por um e outro possui causas distintas. Do ponto de vista psicológico, o entesourador ama o dinheiro em seu perpétuo estado de potência. O capitalista tem por móbil a valorização do valor como uma finalidade em si mesma. O movimento insaciável do capital é um reflexo da sua própria cupidez.
\end{abstract}

PALAVRAS-CHAVE: Capitalista. Dinheiro. Entesourador. Riqueza. Valor.

ABSTRACT: The proposal of this paper is to analyze the distinction established by Marx between "miser" and "capitalist". It rises as a hypothesis that the basis of this difference lies in the purpose of the incessant multiplication of value for both. Each one act for an impulse for enrichment. However, the miser accumulates money as money, while the capitalist accumulates money as capital. While the miser retains money from circulation, the capitalist strives to make money circulate indefinitely. Nevertheless, it is assumed that this incessant multiplication of the value practiced by both has different causes. From a psychological perspective, the miser desires money in its perpetual state of potency. The capitalist takes for granted the valuation of value as an end in itself. The insatiable movement of capital is a reflection of its own cupidity.

KEYWORDS: Capitalist. Miser. Money. Value. Wealth.

Marx (1985), no Livro I de "O Capital”, capítulo quatro, seção dois, ao explicar a transformação de dinheiro em capital e a fórmula geral do capital, estabelece uma distinção entre "entesourador" e "capitalista":

O valor de uso nunca deve ser tratado, portanto, como meta imediata do capitalismo. Tampouco o lucro isolado, mas apenas o incessante movimento do ganho. Esse impulso absoluto de enriquecimento, essa caça apaixonada do valor, é comum ao capitalista e ao entesourador, mas enquanto o entesourador é apenas o capitalista demente, o capitalista é o entesourador racional. A multiplicação incessante do valor,

\footnotetext{
1 Professora Adjunta da Universidade Estadual de Feira de Santana (UEFS). Doutora em Filosofia pela Universidade Estadual de Campinas (UNICAMP). E-mail: adriana_tabosa@yahoo.com.br.
} 
pretendida pelo entesourador ao procurar salvar o dinheiro da circulação, é alcançada pelo capitalista mais esperto ao entregá-lo sempre de novo à circulação (MARX, 1985, p. 129-130).

A partir dessa passagem, é possível perceber os fatores que possibilitam identificar qual é a diferença entre entesourador e capitalista. Marx (1985) diz que nem o "valor de uso" nem o "lucro isolado" são fins para o capitalismo. A sua finalidade é apenas o movimento incessante do lucro monetário. O que há em comum entre o entesourador e o capitalista é apenas o impulso pelo enriquecimento. O meio de locupletação aplicado pelos dois é uma das causas dessa diferença. Enquanto o capitalista busca uma espécie de movimento perpétuo de circulação do dinheiro, o entesourador tem por fim retirar o dinheiro da circulação. Para isso, ele deve deter a mercadoria na sua primeira metamorfose, impossibilitando o dinheiro de realizar a sua finalidade de meio de compra.

O primeiro fator de diferença apontado por Marx (1985) entre entesourador e capitalista refere-se ao método de enriquecimento aplicado. O segundo reside em uma perspectiva psicológica: Marx (1985) afirma que o "[...] entesourador é o capitalista demente" (MARX, 1985, p. 130). Em contrapartida, o “[...] capitalista é o entesourador racional” (MARX, 1985, p. 130). Em outros termos, o entesourador tem por “[...] móbil ativo do entesouramento a avareza" (MARX, 2011, p. 131). Ao passo que o capitalista tem por móbil ativo a cupidez. Apesar de ambos serem movidos pelo desejo de enriquecimento, a relação com o dinheiro e a finalidade do dinheiro, para eles, diferem-se.

Estabelecidas essas considerações, pretende-se neste artigo uma análise da distinção apresentada por Marx (1985) entre entesourador e capitalista, fundamentada em dois aspectos: I) o processo aplicado para a ação da multiplicação incessante do valor, exercido pelo entesourador e pelo capitalista; II) em uma perspectiva psicológica, analisar por que Marx define o entesourador como "capitalista demente" e o capitalista como "entesourador racional". Parte-se do princípio que, apesar de ambos buscarem o mesmo fim, o enriquecimento, a relação final com o dinheiro é distinta entre eles. O entesourador deseja, avidamente, o dinheiro por vêlo como um meio de uma potencialidade perpétua. Enquanto o capitalista deseja o dinheiro por um movimento perpétuo de circulação, um reflexo do ato em si, da sua cobiça.

\section{O processo de multiplicação incessante do valor do entesourador}

Marx (1985) apresenta duas formas de circulação, quais sejam: a “[...] forma direta de circulação de mercadorias (M-D-M)" (MARX, 1985, p. 125), na qual o dinheiro cumpre a sua função de intermediário na relação de compra e venda. Pois, há, inicialmente, a transformação 
da mercadoria em dinheiro e, em seguida, a retransformação do dinheiro em mercadoria. Paralelamente a essa forma, há uma outra espécie de circulação, D-M-D, na qual o princípio da troca se inicia com dinheiro que é transformado em mercadoria e retransformado em dinheiro novamente. No primeiro modo há a venda de uma mercadoria que é um não valor de uso para quem a vende, para obter dinheiro e adquirir uma outra mercadoria que representa um valor de uso. Por essa razão, o movimento M-D-M é completo em si mesmo. O dinheiro que é gerado como produto da venda é utilizado para a compra de outra mercadoria, que terá por fim o consumo. Desse modo, o dinheiro sai da esfera da circulação e transforma-se em mercadoria que será consumida. O segundo tipo de circulação, D-M-D, não tem por objetivo o consumo. O seu fim não é a aquisição de uma mercadoria que será um valor de uso para quem a compra, mas, sim, o dinheiro. Ao contrário da primeira forma, o dinheiro que é lançado em circulação não é gasto, mas apenas renovado. O movimento da circulação não se encerra com a mercadoria, todavia o dinheiro retorna, para novamente ser lançado em circulação. Para Marx (1985), esse dinheiro que é renovado no ato da circulação, transforma-se em capital:

\footnotetext{
Vejamos mais de perto a circulação D-M-D. Ela percorre, como circulação simples de mercadorias, duas fases antitéticas. Na primeira fase, D-M, compra, o dinheiro é transformado em mercadoria. Na segunda fase, M-D, venda, a mercadoria é retransformada em dinheiro. A unidade de ambas as fases é, porém, o movimento global, que troca dinheiro por mercadoria e, novamente, a mesma mercadoria por dinheiro, compra mercadoria para vendê-la, ou, se não consideram as diferenças formais entre compra e venda, compra mercadoria com o dinheiro e dinheiro com mercadoria. $\mathrm{O}$ resultado, em que todo o processo se apaga, é troca de dinheiro por dinheiro, D-D. Se com 100 libras esterlinas compro 2.000 libras de algodão e revendo as 2.000 libras de algodão por 110 libras esterlinas, então troquei afinal 100 libras esterlinas por 110 libras esterlinas, dinheiro por dinheiro (MARX, 1985, p. 126).
}

Segundo Marx (1985), o objetivo dessa forma de circulação é o aumento do dinheiro. Pois, não haveria sentido na realização desse processo, caso a soma do dinheiro lançado inicialmente na circulação fosse a mesma do processo final da circulação. Como não há nenhuma diferença qualitativa entre uma soma de dinheiro e outra, a diferença só pode ser quantitativa; e é este acréscimo quantitativo de dinheiro que constitui a finalidade dessa forma de circulação. A partir dessa explanação Marx (1985) menciona que não é este o processo de circulação aplicado pelo entesourador: "Incomparavelmente mais simples e mais seguro seria o método do entesourador, que retém as suas 100 libras esterlinas ao invés de expô-las ao perigo da circulação” (MARX, 1985, p. 126). Não obstante, o entesourador deseja, avidamente, acumular dinheiro, pois o dinheiro é o "[...] representante concreto da riqueza material" (MARX, 2011, p. 126). O dinheiro é o objeto que satisfaz todas as necessidades, uma vez que 
ele pode se converter em qualquer mercadoria. O dinheiro, para o entesourador, é uma espécie de símbolo de uma potencialidade infinita de valor de troca, já que corresponde, no seu valor de uso, aos valores de troca de todas as mercadorias. Por essa razão, o dinheiro é uma síntese de toda a riqueza social.

Todavia, o método de multiplicação incessante do valor exercido pelo entesourador é, por essência, contraditório. Para ele adquirir dinheiro é necessário manter a mercadoria na esfera da circulação. Pois, apenas na circulação, a mercadoria transforma-se em dinheiro. No entanto, retirar a mercadoria da circulação sob a forma de dinheiro é a única maneira de mantêla, incessantemente, na esfera da circulação. Contudo, a condição da retirada do dinheiro da esfera da circulação é a sua constante substituição pela mercadoria. Ou seja, o entesourador precisa introduzir, constantemente, a mercadoria na circulação. É o processo de venda ininterrupta que caracteriza a primeira condição do entesouramento. Não obstante, o entesourador deve reter o dinheiro da circulação, do contrário este desapareceria no próprio processo de circulação. Em outros termos, o dinheiro, para sair da esfera da circulação, não pode transformar-se em mercadoria novamente. É essa a condição que caracteriza a ação do entesourador - ele deve vender o máximo possível e comprar o mínimo possível:

\begin{abstract}
A apreciação da riqueza na sua forma geral implica assim a renúncia à riqueza na sua realidade material. $\mathrm{O}$ móbil ativo do entesourador é a avareza, que não sente a necessidade da mercadoria como valor de uso, mas sim do valor de troca como mercadoria. [...] $\mathrm{O}$ entesourador despreza os prazeres seculares, temporais e efêmeros, para perseguir o tesouro eterno que não é destruído nem pela traça nem pela ferrugem [...] (MARX, 2011, p. 131).
\end{abstract}

O entesourador subverte a essência do dinheiro não quando o converte em um fim em si mesmo, mas quando o conserva em um perpétuo estado de potencialidade, isto é, em uma eterna potencialidade para adquirir, que não se concretiza. O dinheiro por sua essência é um meio. Todavia, transforma-se em um fim em si mesmo. Para o entesourador, o dinheiro não é apenas um objeto de desejo de enriquecimento, ele é, em si, esse objeto:

No fundo, é o valor de troca, o seu crescimento, que se torna um fim em si. A avareza mantém o tesouro prisioneiro, não permitindo ao dinheiro tornar-se meio de circulação, mas a sede do ouro mantém a alma de dinheiro do tesouro, a constante atração que exerce sobre ele a circulação (MARX, 2011, p. 135).

A atividade do entesourador é um círculo vicioso no qual ele retira o dinheiro da circulação por uma repetição constante da venda e o impede de cumprir a sua finalidade de 
meio de compra, acumulando-o. Transforma o dinheiro em uma perpétua potencialidade de valor de troca irrealizável em ato, desvirtuando o fim pelo qual o foi criado. O entesourador cobiça uma riqueza que termina por não se constituir em riqueza para ele. Cobiça possuir dinheiro como potencialidade de satisfazer todas as necessidades sociais, contudo, em sua cobiça de prazer ilusório, renuncia a qualquer prazer concreto. Ele deseja e se satisfaz apenas em potência ${ }^{2}$.

\section{O processo de multiplicação de valor do capitalista}

O processo de multiplicação do valor praticado pelo entesourador se diferencia do praticado pelo capitalista. Apesar da semelhança do método aplicado por ambos, há algo subjacente que torna os dois processos essencialmente distintos. $\mathrm{O}$ entesourador que tem por móbil ativo a avareza segue o processo de produzir o máximo possível de mercadorias para vender muito e comprar o mínimo possível com o dinheiro adquirido. Em suma, produçãovenda-poupança é o círculo vicioso que fundamenta o seu método de multiplicação do valor. O entesourador não incrementa o dinheiro lançando-o novamente à esfera da circulação. Ele acumula o dinheiro evitando comprar. O entesourador retém o dinheiro pelo dinheiro, o capitalista acumula dinheiro como capital. O capitalista não é o avaro medroso que prefere o método do entesouramento para salvar o dinheiro. O capitalista age como um jogador. Aquele que não tem medo de arriscar em lançar o dinheiro no circuito D-M-D'. O propósito do movimento D-M-D' é que a soma de dinheiro com a qual ele termina seja maior do que aquela que ele começou. O móbil condutor desse movimento é esse incremento do dinheiro:

Portanto, o processo D-M-D não deve seu conteúdo a nenhuma diferença qualitativa de seus extremos, pois ambos são dinheiro, mas apenas à sua diferença quantitativa. No final, mais dinheiro é retirado da circulação do que foi lançado nele no começo. O algodão comprado por 100 libras esterlinas é, por exemplo, revendido a $100+10$ libras esterlinas, ou 110 libras esterlinas. A forma completa desse processo é, portanto, $\mathrm{D}-\mathrm{M}-\mathrm{D}^{\prime}$, em que $\mathrm{D}^{\prime}=\mathrm{D}+\Delta \mathrm{D}$, ou seja, igual à soma de dinheiro originalmente adiantado mais um incremento (MARX, 1985, p. 128).

É esse incremento gerado no processo final dessa forma de circulação que Marx (1985) denomina "mais-valia" (Mehrwert). O capital é, portanto, o valor que gera mais-valia. Nem toda soma de dinheiro, nem toda mercadoria, é capital. O dinheiro só se torna capital se, em seu

\footnotetext{
${ }^{2}$ Xenofonte promove uma reflexão sobre isso quando diz que nem a riqueza é um bem para quem não sabe usála: "Mesmo a terra não é riqueza, se, ao invés de nutrir, faz com que se passe fome. [...] Então o dinheiro, se alguém não sabe usá-lo, que ele o afaste tão longe de si, Critobulo, que não lhe seja riqueza" (XENOFONTE, Econômico, $\mathrm{I}, 8 ; 14)$.
} 
processo de circulação, altera a sua grandeza de valor, se autovaloriza compondo a mais-valia. Esse é o círculo vicioso do capital. A mais-valia não é originada pela circulação simples de mercadoria, tampouco no ato em si da compra e venda. Todavia, ela não é criada fora da esfera da circulação. A mais-valia não se origina no estágio da permuta, mas no momento da circulação de mercadorias que é efetuada pelo dinheiro. A mais-valia aparece na forma dinheiro:

\begin{abstract}
A repetição ou renovação da venda para a compra encontra, como este mesmo processo, mediada e alvo num objetivo final de determinadas necessidades. Na compra e venda, pelo contrário, começo e término são o mesmo, dinheiro, valor de troca, e já por isso o movimento é sem fim. Sem dúvida, de $\mathrm{D}$ adveio $\mathrm{D}+\Delta \mathrm{D}$, das 100 libras esterlinas, $100+10$. Mas consideradas apenas qualitativamente, 110 libras esterlinas são o mesmo que 100 libras esterlinas, ou seja, dinheiro. E considerados quantitativamente, 110 libras esterlinas são uma soma tão limitada de valor quanto 100 libras esterlinas. Se as 110 libras esterlinas fossem gastas como dinheiro, deixariam de desempenhar o seu papel. Deixariam de ser capital (MARX, 1985, p. 128).
\end{abstract}

O dinheiro incrementado nesse processo de circulação não é gerado de um mero aumento no valor da mercadoria de modo que, como menciona Marx (1985, p. 128), corre o risco de trocar "[...] dinheiro por dinheiro"”. A partir dessa consideração, é possível perceber a diferença essencial entre os métodos de multiplicação de valor exercidos pelo entesourador e pelo capitalista. A diferença essencial consiste na mais-valia. No método aplicado pelo entesourador, o dinheiro não se autovaloriza. Ele não engendra de si mais dinheiro. $\mathrm{O}$ entesourador retém o dinheiro. E, uma vez retirado de circulação, ele se petrifica em tesouro. A acumulação do entesourador reside apenas no processo de ganhar dinheiro vendendo e evitando comprar, conservando o dinheiro. Mas o dinheiro acumulado pelo entesourador é "estéril". O capitalista descobriu em seu processo de multiplicação do valor uma maneira mais engenhosa de enriquecimento. Ele não precisa se privar de comprar, pois ele conseguiu, com a fórmula geral do capital, fazer com que o dinheiro gere dinheiro ${ }^{4}$. O dinheiro nas mãos do capitalista

\footnotetext{
${ }^{3}$ Kautsky exemplifica esse problema da seguinte maneira: "Por 90 s, um comerciante compra de um agricultor 4 toneladas de batatas que valem 100 centavos e as vende para o alfaiate por $110 \mathrm{~s}$. Ao final do processo, o comerciante encontra em suas mãos um valor maior do que o inicial. Mas a soma dos valores existentes permanece a mesma. No início temos o valor de $100 \mathrm{~s}$ (do agricultor), mais $90 \mathrm{~s}$ (do comerciante), mais $110 \mathrm{~s}$ (do alfaiate) = $300 \mathrm{~s}$. Ao final do processo, os $90 \mathrm{~s}$ (do agricultor), mais $110 \mathrm{~s}$ (do comerciante), mais $100 \mathrm{~s}$ (do alfaiate) $=300 \mathrm{~s}$ " (KAUTSKY, Karl. The Source of Surplus-value. In: KAUTSKY, K. The economic doctrines of Karl Marx. Transleted by H.J. Stenning. A. \& C. Black, LTD. London: England, 1925, p. 57. Disponível em: https://archive.org/details/in.ernet.dli.2015.264093/page/n1. Acesso em: 26/mar/2019.

${ }^{4}$ A usura constitui para Aristóteles a forma de aquisição mais contrária à natureza. A usura representa uma das formas da crematística. Ela consiste em multiplicar o dinheiro a partir do próprio dinheiro: "Com muito mais razão se detesta a prática de cobrar juros, porque nela o ganho resulta do dinheiro propriamente dito e não da finalidade para o qual o dinheiro foi instituído. Ora, o dinheiro foi instituído para a troca, enquanto o juro
} 
tornou-se fértil. Dessa finalidade em si mesma, característica do capital, a valorização do valor se perpetua nesse movimento sempre renovável e insaciável:

\begin{abstract}
O valor tornou-se, portanto, valor em processo, dinheiro em processo e, como tal, capital. Ele provém da circulação, entra novamente nela, sustenta-se e se multiplica nela, retorna aumentado dela e recomeça o mesmo ciclo sempre de novo. D-D', dinheiro que gera dinheiro - Money wich begets Money -, diz a descrição do capital na boca de seus primeiros tradutores, os mercantilistas (MARX, 1985, p. 131).
\end{abstract}

Marx (1985) identifica o enigma da mais-valia numa mercadoria, cujo valor de uso tem como característica peculiar a propriedade de ser uma fonte inesgotável de valor, o trabalho ${ }^{5}$. A fórmula geral do capital é realizada quando a força de trabalho é convertida em mercadoria. Para Marx (1985), o valor de uma mercadoria é determinado por algo comum entre os objetos trocados. Esse algo é uma "substância comum"; a troca, quantitativamente determinada para Marx, pressupõe uma “igualdade de essências” entre os objetos trocados. É necessário que exista uma substância ou essência comum, algo essencialmente quantificável, para que possa haver troca. Essa substância ou essência comum é algo subjacente no processo das trocas e torna-se perceptível, unicamente, quando se faz a abstração de suas diferenças sensíveis. O que esses objetos possuem em comum além de seu valor de uso, e que não se mostra sensivelmente, é que são "produtos do trabalho humano". O trabalho é, portanto, essa substância que os objetos contêm. O trabalho representa o "quantum" presente em cada um dos objetos e que determina as proporções da troca (MARX, 1985, pp. 47-53).

Como foi explanado anteriormente, para se tornar uma mercadoria um valor de uso não deve ser valor de uso para o vendedor da mercadoria. Do mesmo modo, a força de trabalho não deve ser um valor de uso para o trabalhador. Quando a força de trabalho se converte em mercadoria, os trabalhadores devem ser separados (Entfremdete Arbeit) dos meios de produção. O capitalista é o detentor dos meios de produção. Ele deseja que a sua fonte de enriquecimento seja inesgotável, contudo, o trabalhador é finito. Para o capitalista aplicar a sua "irracionalidade econômica" , a classe trabalhadora deve perpetrar a sua espécie do mesmo modo que o dinheiro

multiplica a quantidade do próprio dinheiro. É essa a origem do termo juro: os seres gerados assemelham-se aos seus progenitores e o juro é dinheiro nascido do dinheiro. Assim, de entre todos os modos de adquirir bens, este é o mais contrário à natureza (Pol. I, 10, 1258 b, 1-5). Na Idade Média, o argumento de Alberto Magno, de que o dinheiro não pode engendrar do dinheiro (nummus non parit nummos) e o juro é contrário à natureza das coisas, foi fundamentado em Aristóteles.

${ }^{5}$ Não será possível, por causa do espaço e delimitação temática deste artigo, desenvolver toda uma análise do desvelamento da relação entre mais-valia e trabalho.

6 Julga-se que o capitalista segue a mesma atitude demonstrada por Aristóteles sobre os que praticam a crematística: “[...] a faculdade associada à crematística não é uma inclinação em virtude (Et. Nic. II, 5,1105 b, 1 2), mas uma inclinação ao vício, o vício correspondente à concupiscência, que é uma parte irracional da alma (Et. 
deve gerar dinheiro, no processo ilimitado da fórmula geral do capital. O movimento insaciável de enriquecimento do capitalista é um sintoma da sua própria cupidez.

\section{A teleologia do dinheiro - a avareza e a cupidez, os vícios do entesourador e do capitalista}

Resta discorrer sobre o segundo aspecto da diferença estabelecida por Marx (1985) entre entesourador e capitalista, aquela que envolve a finalidade do dinheiro sob uma perspectiva psicológica. Conforme foi mencionado anteriormente, Marx (1985) afirma que o "[...] impulso absoluto de enriquecimento" (MARX, (1985, pp. 129-130) é comum ao entesourador e ao capitalista. Em seguida, define o entesourador como o "capitalista demente" e o capitalista como o "entesourador racional". Essa diferença, sob uma perspectiva psicológica, manifesta-se quando Marx (1985) afirma que o entesourador tem por "móbil ativo a avareza" (MARX, 2011, p. 131) enquanto o capitalista é o "portador consciente" de um movimento que é "insaciável”. Para Marx (1985), “[...] a valorização do valor é a meta subjetiva” do capitalista (MARX, 1985, p. 129): “[...] A apropriação crescente da riqueza abstrata é o único motivo indutor de suas operações” (MARX, 1985, p. 129). Por essa razão, o capitalista age como o “capital personificado, dotado de vontade e consciência" (MARX, 1985, p. 129).

A partir dessas considerações estabelecidas por Marx (1985), é possível identificar que enquanto a disposição que move o entesourador ao impulso de enriquecimento é a sua avareza, o capitalista tem por "móbil ativo" a cupidez. O método de multiplicação do valor praticado pelo entesourador é, portanto, um reflexo da sua avareza. O entesourador retém o dinheiro porque cobiça a sua possibilidade de uso ilimitado. Ele cobiça o dinheiro porque ele é, por sua essência, o equivalente geral de todas as mercadorias. No entanto, seu desejo de dinheiro é contraditório $^{7}$. O entesourador cobiça o dinheiro na condição de uma perpétua potencialidade de valor de troca irrealizável em ato:

\footnotetext{
O nosso entesourador apresenta-se como o mártir do valor de troca, santo asceta empoleirado na sua coluna de metal. Só lhe interessa a riqueza na sua forma social e é por isso que na terra a põe fora do alcance da sociedade. Quer a mercadoria sob a forma que a torna constantemente apta à circulação, e é por isso que a retira da circulação. Sonha com o valor de troca, e é por isso que não faz trocas. A forma fluida da riqueza e sua forma petrificada, elixir da vida e pedra filosofal, combinam-se na fantasmagoria de uma louca alquimia (MARX, 2011, p. 136).
}

Nic. I, 13, 1102 b, 1 e s.) que preside os impulsos, os desejos, as necessidades e concerne ao corpo. Segundo Aristóteles, a vida dedicada a ganhar dinheiro é vivida sob compulsão (Et. Nic. I, 5, 1096 a, 7).

${ }^{7}$ Por sua essência, o próprio dinheiro é contraditório, como afirma Simmel: "[...] ele é um meio absoluto que, por esta razão mesma, se eleva ao significado psicológico de um fim absoluto" (SIMMEL, Georg. 2009, p. 283). 
Ao passo que o capitalista é um concupiscente, aquele que persegue o dinheiro sempre em vista de algo mais. A sua busca incessante por dinheiro é uma compulsão. Por isso Marx (1985) define o capitalista como o "capital personificado", uma vez que o "[...] movimento do capital é insaciável” (MARX, 1985, p. 129). O método de enriquecimento do capitalista é, portanto, um reflexo da sua própria cupidez. A cupidez do capitalista e a avareza do entesourador são fenômenos convergentes. Ambos têm em comum a aquisição do dinheiro como finalidade absoluta. Não obstante, a avareza do entesourador identifica no dinheiro um prazer que é distinto ao da cupidez do capitalista. Ambos, entesourador e capitalista, invertem a ordem do ter e ser. $\mathrm{O}$ ser para eles converte-se em ter dinheiro ${ }^{8}$.

A distinção entre os métodos de multiplicação do valor do entesourador e do capitalista se desvela mediante característica peculiar de seus respectivos vícios. O entesourador, assim como o capitalista, cobiça o dinheiro por ser o equivalente de todos os valores. Contudo, renuncia a usar o dinheiro como meio para obter qualquer prazer. O seu prazer é uma forma abstrata de prazer que não é experimentado. O prazer para o entesourador é um revérbero do que é o próprio dinheiro. Pois, assim como o dinheiro é um meio absoluto em ato, conversível em um fim absoluto em potência, o prazer do entesourador é a retenção de uma expectativa de posse que não se concretiza:

\begin{abstract}
Estes dois momentos alcançam na avareza a sua máxima tensão mútua, porque o dinheiro, meio absoluto, abre possibilidades ilimitadas de prazer, e ao mesmo tempo, sendo um meio absoluto, ele mantém em sua posse não utilizada o prazer totalmente intacto. Sob este aspecto, o significado do dinheiro coincide com o da potência; assim como ela, ele é uma simples capacidade de reunir as atrações de um futuro que só se pode antecipar subjetivamente na forma de um presente que está objetivamente ali (SIMMEL, 2009, p. 288-289).
\end{abstract}

O dinheiro, para o entesourador, não tem outra finalidade que não seja apenas a sua posse. O seu prazer consiste numa inversão ontológica do dinheiro, isto é, cobiça possuir dinheiro por causa da sua função de meio de compra, mas renuncia à riqueza na sua realidade material, já que considera mesmo as necessidades particulares um luxo supérfluo. Para o entesourador, o processo teleológico do dinheiro é petrificado. Pois, ele age como uma valorização que, em si, não corresponde a uma finalidade realizável, em um processo contraditório à sua própria teleologia.

\footnotetext{
${ }^{8}$ Platão nomeia o desejo de ter mais do que a parte justa de qualquer coisa e, sobretudo, mais do que os outros, de pleonexia. (Rep., II, 358c 3-4). Para Platão, o dinheiro se torna uma espécie de dispositivo dos anseios de aquisição, desvirtuando o sentido mesmo de riqueza. A riqueza monetária deixa de ser um meio para o bem viver para se tornar o resultado de uma acumulação desvirtuada, um signo exterior da pleonexia. Nos apetites, segundo Platão, o ter substitui o ser por uma medida de aparência sensível. O "ter", sejam os bens ou uma posição social, seria o signo do ser. Por essa razão a pleonexia se manifesta na busca incessante pelo enriquecimento e pela ostentação, uma vez que, para "sentir-se superior", é necessário "ter mais que" os outros e o exibir.
} 
Para o capitalista, o dinheiro torna-se um dispositivo da sua cupidez. O seu desejo de possuir coisas é ilimitado, por isso ele cobiça um instrumento que deve ser multiplicado, incessantemente. A velocidade da multiplicação do dinheiro deve acompanhar a voracidade de seus apetites.

O cúpido deseja todas as coisas que promovem prazer e é conduzido por sua incontinência a buscá-las. Ele vive em um contínuo estado de ansiedade para adquirir o que possibilita prazer. O que é paradoxal, uma vez que sofre em busca desse prazer ${ }^{9}$. O capitalista, movido por sua cupidez, cobiça o dinheiro porque a sua posse significa uma possibilidade de gozar de uma quantidade indeterminada de coisas. O dinheiro, por sua vez, eleva a ideia geral de propriedade a uma potência superior, a ideia que quem possui dinheiro está diante de uma infinidade de objetos. O capitalista "sorri" (MARX, 1985, p. 160) porque encontrou uma maneira engenhosa de multiplicar, indefinidamente, dinheiro:

\begin{abstract}
O produto - a propriedade do capitalista - é um valor de uso, fio, botas etc. Mas, embora as botas, por exemplo, constituam de certo modo a base do progresso social e nosso capitalista seja um decidido progressista, não fabrica as botas por causa delas mesmas. [...] E para o nosso capitalista, trata-se de duas coisas. Primeiro, ele quer produzir um valor de uso que tenha um valor de troca, um artigo destinado à venda, uma mercadoria. Segundo, ele quer produzir uma mercadoria cujo valor seja mais alto que a soma dos valores das mercadorias exigidas para produzi-la, os meios de produção e a força de trabalho, para as quais adiantou seu bom dinheiro no mercado. Quer produzir não só um valor de uso, mas uma mercadoria, não só valor de uso, mas valor e não só valor, mas também mais-valia (MARX 1985, p. 155).
\end{abstract}

Marx (1985) define o capitalista como a "personificação do capital” (MARX, 1985, p. 129). Há, contudo, uma espécie de simbiose. O movimento do capital só existe por causa do seu agente. Em contrapartida, o capitalista depende do movimento do capital para multiplicar, incessantemente, o dinheiro, o instrumento que é o dispositivo da sua cupidez. O capitalista conduz esse movimento que é o seu círculo vicioso: dinheiro - mercadoria - mais dinheiro. Por causa de uma transformação contínua das formas dinheiro e mercadoria, o valor altera a sua própria grandeza, se autovaloriza. A mais-valia é, essencialmente, o movimento da valorização do dinheiro, isto é, de sua autovalorização.

\title{
Conclusão
}

Em uma análise resumida, o presente artigo discorreu sobre a distinção estabelecida por Marx (1985) entre entesourador e capitalista, fundamentando a abordagem com base em

\footnotetext{
${ }^{9}$ ARISTÓTELES, Et. Nic. III, 1119 a, 5.
} 
dois aspectos: primeiro, o processo aplicado para a ação da multiplicação incessante do valor, exercido pelo entesourador e pelo capitalista; segundo, uma perspectiva psicológica, a fim de compreender por que Marx define o entesourador como "capitalista demente" e o capitalista como "entesourador racional". A análise objetivou mostrar que, apesar de ambos almejarem o mesmo fim, o enriquecimento, a relação final com o dinheiro é distinta entre eles. $\mathrm{O}$ entesourador deseja, avidamente, o dinheiro, por vê-lo como um meio de uma potencialidade perpétua, enquanto o capitalista deseja o dinheiro por um movimento perpétuo de circulação.

O que há em comum entre o entesourador e o capitalista é a busca incessante da multiplicação do dinheiro. O dinheiro, para ambos, constitui-se como um instrumento que compreende o desejo da totalidade e o processo do prazer. Apoiam-se um no outro, reforçamse mutuamente. $O$ dinheiro passa a ser perseguido pelo entesourador como um meio e um fim, simultaneamente, pois é, em potência, o equivalente de todas as coisas. Porém, o entesourador cobiça o dinheiro na condição de uma perpétua potencialidade de valor de troca irrealizável em ato. O capitalista também cobiça o dinheiro como um meio e um fim, simultaneamente. Contudo, não petrifica o dinheiro numa condição de perpétua potencialidade do valor de troca. Ele usa-o para adquirir por compulsão. O dinheiro é um simulacro desta totalidade que tem em vista os apetites, e esta convertibilidade universal do dinheiro explica a ação do capitalista. A busca ilimitada de enriquecimento monetário pelo entesourador e pelo capitalista é um sintoma de suas respectivas patologias ${ }^{10}$. A avareza do entesourador e a cupidez do capitalista são patologias quando revelam seus respectivos paradoxos - o sofrimento em busca do prazer. O prazer do entesourador é um prazer ilusório, que nunca se realiza em ato. Ele retém o dinheiro por causa da sua função de meio de compra, mas renuncia à riqueza na sua realidade material. Ostenta uma riqueza que, na realidade, não se constitui riqueza para ele. $\mathrm{O}$ capitalista cobiça o dinheiro por ser este um instrumento e um simulacro de seus apetites. Compra por compulsão, acumulando, indefinidamente, a riqueza na realidade material. Todavia, não lhe resta tempo para usufruir dessa riqueza, pois perde-se no movimento do capital, tornando-se um sujeito automático, para quem o fim de suas ações é, meramente, a multiplicação incessante da riqueza, contrastando com o limite de sua própria finitude.

\footnotetext{
${ }^{10}$ Essa é a tese defendida por Aída Aisenson Kogan e Fanny S. Y. de Hoffer (2005), em suas pesquisas, publicadas na obra: El mal dinero: reflexiones sobre la codicia y la avaricia.
} 


\section{REFERÊNCIAS BIBLIOGRÁFICAS}

\section{Referências básicas:}

MARX, Karl. O capital: crítica da economia política. Trad. de Regis Barbosa; Flávio R. Kothe. $2^{\mathrm{a}}$ ed. São Paulo: Nova Cultural, 1985.

Contribuição à crítica da economia política. Trad. Maria Helena Barreiro Alves; Carlos Roberto F. Nogueira. $4^{\mathrm{a}}$ ed. São Paulo: Martins Fontes, 2011. (Clássicos WMF).

\section{Referências complementares:}

ARISTÓTELES. Ética a Nicômacos. Trad. Mário da Gama Kury. Brasília: Editora Universidade de Brasília, 4ª ed., 2001.

ARISTÓTELES. Política. Trad. António Campelo Amaral; Carlos de Carvalho Gomes. Lisboa: Vega Universidade/Ciências Sociais e Políticas, 1998.

KAUTSKY, Karl. The Source of Surplus-value. In: KAUTSKY, Karl. The economic doctrines of Karl Marx. Transleted by H.J. Stenning. A. \& C. Black, LTD. London: England, 1925. Disponível em: https://archive.org/details/in.ernet.dli.2015.264093/page/n1. Acesso em: 26/mar/2019.

KOGAN, Aída Aisenseon.; HOFFER, Fanny. S. Y de. El mal dinero: reflexiones sobre la codicia y la avaricia, Buenos Aires: Biblos, 2005.

PLATÃO. A república. Trad. Maria Helena da Rocha Pereira. 7. ed. Lisboa: Fundação Calouste Gulbenkian, 1995.

SIMMEL, Georg. Philosophie de l'argent. Trad. Sabine Cornille; Philippe Ivernel. Paris: Presses Universitaires de France, 2009.

XENOFONTE. Econômico. Trad. Anna Lia Amaral de Almeida Prado. São Paulo: Martins Fontes, 1999. 